\title{
A Brief Review on Inflight Wi-Fi
}

\author{
Akshatha $\mathbf{M}^{1}$, Seema $\mathbf{H} \mathbf{R}^{2}$ \\ ${ }^{1,2}$ Vidya Vikas Institute of Engineering and Technology
}

\begin{abstract}
The Airline industry is now experiencing rapid change with respect to the provision of in-flight entertainment and connectivity between the devices and air plane. Wireless IFE (In Flight Entertainment) streamed to personal/portable electronic devices (PEDs), has the potential to modify the traditional business model. Meanwhile, connectivity has arrived and, in the US at least, is already an established offering on domestic flights. In other parts of the world, connectivity is also gaining a foothold, but many airlines are still wary of making the substantial investment required to equip their fleets
\end{abstract}

Keywords: Inflight wifi, IATA, Exede, GoGo

\section{Introduction}

Technology is making rapid progress as the innovative thinking of people is increasing day-by-day, new methods for wireless networking has been evolved of which our present topic Wi-Fi is the most accepted technology.

Passenger surveys show growing demand for connectivity in the cabin. IATA's 2014 global passenger survey reveals that $80 \%$ of the passengers would use Wi-Fi if offered on board a flight. According to the 2014 APEX passenger experience study,

1 in 3 passengers indicated that in-flight connectivity is the single most needed area of improvement by airlines while $90 \%$ of passengers would give up other amenities to have a better in-flight internet experience. Back in the dinosaur days, being on an airplane meant being disconnected from everything and everyone. No friends. No family. No work. But with the advent of inflight Wi-Fi, now you can do what needs to be done and have some time left over for those cat videos - hey, we don't judge. Once your Wi-Fi enabled plane is above 10,000 feet, simply choose the appropriate inflight Wi-Fi network from your available network list to $\log$ in. There's no need to create a separate account or sign up with your credit card to access the inflight service. Inflight connectivity services have evolved and consumers want to Browse the web and stream video more like their home experience. Only ViaSat, by leveraging our leadership in high-capacity Ka-band satellite technology, is poised to respond to the simultaneous growth of take rate and bandwidth demanded by passengers. The Exede service is capable of delivering $12 \mathrm{Mbps}$ to each passenger on the plane no matter how many connect. Competing in-flight services are based simply on an aggregate amount of bandwidth to the plane that leaves passengers contending for service. With the Exede service, airlines can let business and leisure travelers do more in the air than they thought was possible, including video chats and streaming media. This is the only service that lets everyone use the Internet the way they want. Our service offers the best experience to the passenger while the economics of Ka-band give a sustainable advantage to the airline. Mobile phones have been a common feature of many people's lives since the mid-1990s, but for much of the time since, they've been banished from the world of air travel. It's almost become second nature to just switch devices off when entering an aircraft - that was until handset manufacturers began loading their products with an intriguing new feature called _flight mode‘. By removing the majority of signal-transmitting capabilities, this setting allows passengers to use their devices without any risk of interfering the aircraft's internal systems. This was obviously a significant step forward but there's still something major missing: connectivity.

\section{Current Situation}

As the air travel market expands and price wars become heated, it's natural for airlines to want to meet the needs of their customers. It is for this reason that many have invested in the early stages of on-board Wi-Fi.

It is thought that wireless internet access is now available on 40 per cent of all flights in the US, as well as some long-haul routes operated by European carriers such as Lufthansa, Norwegian and Turkish Airlines. Passengers flying with some of these companies can even connect without charge.

This is all well and good but with access so readily available on the ground, it's clear that there's a lot of work to be done before aircraft cabins catch up with the coffee shops, libraries and tourist attractions a little closer to sea level. What's more, even the connections that do exist are substandard, acting as a source of frustration for many.

\section{Challenges}

The two main issues affecting the current state of Wi-Fi in air travel are rooted in quality and accessibility. As mentioned, only a handful of flights do offer Wi-Fi at present and this is not nearly enough to cater for such a massive, global Smartphone market.

Quality is severely lacking in the services which are available. On land, Wi-Fi is preferred by most smartphone users because it offers better speed and reliability than the average mobile data connection - whether $3 \mathrm{G}$ or LTE. In the air, where mobile internet isn't at all accessible, these benefits rarely exist; connections are often slow and intermittent.

The general dissatisfaction is evidenced by the results of a recent Flight View study. After questioning more than 600 American business travelers, the aircraft-tracking service 


\section{International Journal of Science and Research (IJSR) \\ ISSN (Online): 2319-7064}

Index Copernicus Value (2015): 78.96 | Impact Factor (2015): 6.391

found that only 28 per cent are happy with the Wi-Fi services they have access to when flying.

Cost is another concern - with progress in this area of technology prone to stalling, most travelers are forced to pay significant fees in return for access. This can, in some cases, be as high as $£ 15$ for a single flight.

In order to get a better idea of why the obstacles are proving so difficult to maneuver, it helps to understand the basic technological concepts.

\section{Methodology}

When carriers make the decision to invest in Wi-Fi, they have two main routes to consider; essentially, they must pick between the ground and the sky.

One option would be to use a network of $4 \mathrm{G}$ and $3 \mathrm{G}$ ground stations to which planes can connect as they pass overhead. Sharing many characteristics of standard land-based mobile data infrastructure, this approach is simple and relatively well-researched. Bandwidth, however, is severely limited, meaning users are restricted to just basic tasks - at present, streaming HD movies is certainly out of the question.

There's also potential to consider in satellite connectivity. Back in January, the UK's media regulator, Ofcom, authorized the use of earth stations on aircraft, as well as boats and trains. When mounted to the vehicle, these devices can provide Wi-Fi by connecting to geostationary satellites. Of course, the success of such an approach will lie, to some extent, on electromagnetic spectrum provision.

To this end, Ofcom has already said that it will dedicate a considerable amount of high-frequency spectrum to ensure the technology's potential is reached. It is thought that the first licenses for its use will be awarded this year.

\section{Future}

Both of the most obvious approaches have their downsides, but there's also plenty of potential to be realized and development is ongoing. For example, GoGo, which provides access via a countrywide network of $3 \mathrm{G}$ points, has already started rolling out its new ATG-4 technology. By equipping aircraft with directional antennae and dual modems, the company says it can offer connection speeds of up to $9.8 \mathrm{Mpbs}$; not quite HD-streaming speed but it's a big step in the right direction.

In terms of the satellite approach, regulatory bodies around the world are working constantly to unload spectrum for numerous new technologies - in-flight Wi-Fi included. As progress is made with these efforts, accessibility will undoubtedly improve

\section{Wi-fi Variants}

There are two primary methods to enable a passenger Internet connection on an airplane: satellite and air-to- ground. I'll talk about some of the key points on each of those, then talk about the in-cabin Wi-Fi access point part.

\subsection{Air-to-ground}

- As the name implies, signals go from the airplane directly to antennas on the ground

- Uses a network of ground cell towers across the continental U.S. (therefore does not work over water). These towers' cells are much larger than those of the typical cell towers used for phones.

- Uses a version of CDMA, just like Verizon cell phones

- Antennas are on the belly of the airplane, looks like a small fin

- As the airplane flies, the connection hands off from one tower to the next just like your phone does when you're driving. Users don't notice any interruption.

- Network infrastructure is much cheaper than satellite

- Bandwidth for the newest generation system (ATG4) is up to 9.8 megabits per second (Mbps) per airplane (shared across all users). This is enough for email and casual web surfing, but would get quickly exhausted if people stream video - so this is usually blocked. See [3] below.

- Gogo is the top provider of this type of service [1]

- Installed on over 1,000 aircraft operating on domestic routes in the U.S., including Delta, American, Virgin America, and Alaska [2]

- Plans announced in late 2014 by Inmarsat to partner with Gogo on a hybrid ATG + satellite solution for Europe

\subsection{Satellite}

- Unlike air-to-ground, signals from the airplane go into space to an orbiting satellite and then down to the ground. These satellites are usually in geostationary orbit, 22,300 miles up.

- Three types offer different levels of performance (bands indicate specific transmission frequency ranges):

○ L-band (e.g. Inmarsat Swift Broadband): pretty slow, max $422 \mathrm{kbps}$ per channel per airplane

○ Ku-band (e.g. Panasonic, Global Eagle, and Gogo): tops out at around $20-40 \mathrm{Mbps}$ per airplane. Speeds depend on how many airplanes are in the satellite's transponder "footprint" (aka spot beam)

- Ka-band (near future, satellites launching soon): promises even higher speeds

- A modern satellite has dozens of transponders to support a large number of simultaneous connections, e.g. ships, airplanes, portable ground terminals

- Leasing transponders (antennas) on satellites is very expensive, so this cost is usually passed on to the airline and the passengers. But Jetblue offers it for free.

- The airplane's antenna is on the top of the fuselage, under a bubble-shaped roadmen

- Only choice for trans-oceanic routes, and routes flying closer to the polar region (since you can't put cell towers in the ocean)

- Using satellites means a few hundred milliseconds more latency since the data packets need to go 22,300 miles up to the satellite, then roughly 22,300 miles back down to the airplane. New constellations of low earth orbit (LEO) satellites providing lower latency high bandwidth 


\section{International Journal of Science and Research (IJSR) \\ ISSN (Online): 2319-7064}

Index Copernicus Value (2015): 78.96 | Impact Factor (2015): 6.391

connections are in development since 2015, e.g. by SpaceX.

- Installed base not large yet but growing, targeted initially for routes between the U.S. and Europe

- As the airplane flies, the antenna on the top of the plane is steered or electronically aimed to stay pointed at the correct transponder on the satellite up in orbit. For longhaul flights, there will likely be a handoff from one satellite to another when moving between coverage areas. This happens via coordination on the ground, and the airborne users may only notice a very brief hiccup. From the satellite's viewpoint, it switches airplanes from one transponder to the next as it moves between the beams pointed at the ground.

- If you want more technical detail, here is a very nice presentation put together by Panasonic on use of Ku-band for airplanes: [5]

\section{Variants-2}

There are types of WIFI on planes( some are US only )

- Air-To-Ground (ATG) - delivers peak speeds of 3.1Mbps, using cellular-based technologies. It operates in the $3 \mathrm{GHz}$ spectrum, beaming $3 \mathrm{G}$ signals from the ground into the sky from over 200 towers within the U.S. and Canada. 1,500 commercial aircraft use this somewhat obsolete system, likely including those old MD-80s on their way out to the desert.

- ATG-4 - the next generation air-t0-ground technology, launched in November 2012. American, Delta, U.S. Airways and Virgin America have this on a select number of their planes. It bumps the potential connection speed up to $9.8 \mathrm{Mbps}$ by using a directional antenna which moreefficiently captures the beam being sent up from the tower at ground level.

- $\mathrm{Ku}$ - Rather than having an antenna mounted to the bottom of the plane, receiving a signal from the ground, it is actually a $12-18 \mathrm{GHz}$ band within the microwave frequency spectrum. For $\mathrm{Ku}$ connectivity, an antenna is mounted onto the top of the plane, under a radome. The antenna transmits data rates at $10-30 \mathrm{Mbps}$ to the aircraft. Gogo $\mathrm{Ku}$ is currently installed on 15 international Delta Air Lines planes, and some Japan Air Lines planes as well.

- Ground to Orbit (GTO) - a hybrid technology that Gogo( a in-flight connectivity and entertainment provider for Alaska, American, Delta, United, U.S. Airways and Virgin America) unveiled last September, promising speeds of $60 \mathrm{Mbps}$ or higher, for planes flying in North America. It uses a combination of a satellite antenna on top of the plane to receive the signal and the ATG antenna under the plane to return the signal to earth. So technically, it's Orbit to Ground, but that's not nearly as catchy. During a speed test demonstration, download speed peaked at $46.52 \mathrm{Mbps}$.

- $2 \mathrm{Ku}$ - the next generation of connectivity. Gogo says it will deliver speeds topping $70 \mathrm{Mbps}$. It uses dual $\mathrm{Ku}$ antennas - Thinkom's ThinAir Falcon Ku3030. One antenna will receive the signal and transmit it to the aircraft, while the other will transmit the return link to the ground. It will also go on top of the plane, under a relatively thin $17 \mathrm{~cm}$ high radome. The radome height is important, because the higher it is, the more fuel-burning drag it creates.[1]

\section{Pros}

Working flights: People who fly for work often have a lot on their plates. The ability to have access to all your contacts and information is precious (and can be a leg up on people who fly on WiFi-less planes). According to a quick poll of passengers in Air Canada's Maple Leaf Lounge at Toronto's Pearson airport this week, business-class travellers are almost universally in favour of midair connectivity.

Elizabeth McAlister, a UN international development consultant on her way across the Atlantic on Lufthansa, said her job involves reading endless documents that refer to other documents; being able to jump between them is invaluable. (Lufthansa is the only transatlantic airline serving Canada that offers full WiFi service.)

Entertain yourself: Air Canada's inflight entertainment is good, but most airlines have sparse offerings. Unless you are really sorry you missed 10,000 B.C. in the theatres, wouldn't you like the option to catch some BuzzFeed slideshows or sign onto Netflix?

De-stress: According to one Boeing study, more than 30 per cent of people are either anxious or outright afraid of flying. Having access to e-mail, your Facebook page and soothing pictures of kittens in cups can help calm shattered nerve

\section{Cons}

Working flights: For busy flyers, cabin-time can be a palate cleanser: It's often the only quiet part of a road warrior's day. Ray Dowbenko, who was travelling to Paris on Air Canada, is not overtly opposed to inflight WiFi, but finds its utility overrated. - Morld is not going to fall apart from Toronto to Beijing," he said.

Entertain yourself: Though WiFi services have the ability to block content according to an airline's requests, no filter is fool-proof, which means that someone, somewhere on your flight will find porn. Do you want to be sitting next to him?

Missed connections: Sometimes, all you want is to talk to someone. And though some flyers cringe at the thought of a chatty seatmate, connections you make on planes can be valuable: As attests, the social and romantic possibilities are endless. But chances for any of this are greatly diminished if the person sitting next to you can chat online with people she already knows.

\section{Research Direction}

In this paper, we first introduced three common methods of reducing negative physical and psychological stress during air travel. After that, we check how the current in-flight entertainment systems are designed and implemented relating to these three stress reduction methods. Then, the state of the art of enabling technologies that could enable a 


\section{International Journal of Science and Research (IJSR) \\ ISSN (Online): 2319-7064}

Index Copernicus Value (2015): 78.96 | Impact Factor (2015): 6.391

better in-flight entertainment system to improve the passenger's comfort level is investigated. We believe that in order to develop a new context-adaptive system to provide passenger's preferred entertainment services to reduce his/her negative stress intelligently and effectively, the

Following research problems should be addressed first:

11.1.1 .A conceptual control framework of user preferred music provision to reduce the passenger's negative psychological stress intelligently. The research challenge is that the passenger himself/herself is an adaptive system (e.g., user preferred music depends on the context of use and changes with time), so how to design a control framework that could couple the passenger's a the entertainment system's adaptive behaviors to provide the passenger with desired services is not a trivial task.

11.1.2. A user profile model which is pertinent to the desired adaptive behaviors of the context-adaptive in-flight entertainment system. The research challenge lies in user's music preference modeling and tracking and updating its changes.

11.1.3. User preference learning algorithms that could track and even predict" passenger's preference change. In order to produce superior results, user's explicit and implicit feedback and context of use all need to be considered.

11.1.4. New game console solution where if the passenger wants to play the recommended games, he must move like exercises tips which are recommend by the airlines. The research challenge is the limited space of the aircraft seat; moreover, the passenger's game playing behaviors can't bother other passengers and endanger the safety of the aircraft

\section{References}

[1] http://www.wballiance.com/in-flight-wi-fi-review/

[2] https://pdfs.semanticscholar.org/a126/4c1b07a8422c415 c722a675f2d7692f9e4e8.pdf

[3] wemetonaplane.com

[4] http://www.theglobeandmail.com/life/travel/travelnews/is-inflight-wifi-a-blessing-orcurse/article6397098/

[5] http://airfax.com/blog/wp-conten..

\section{Author Profile}

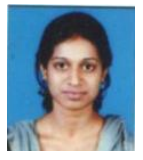

Akshatha M received the B.E degree in Computer Science and Engineering from Sahyadri College of Engineering and Management in 2012 and M.Tech. degree in Networking and Internet Engineering from Jawaharlal Nehru National Institute of Technology in 2014, respectively. During 2014-2015, she stayed in PESCE working as an Assistant Professor. She is now with Vidya Vikas Institute of Engineering and Technology.

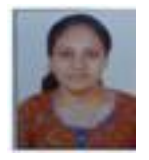

Seema $\mathbf{H} \mathbf{R}$ received the B.E degree in Computer Science and Engineering in 2011 and M.Tech. degree in Computer Networking in 2014, respectively. During 2014-2015, she stayed in PESCE working as an Assistant Professor. She is now with Vidya Vikas Institute of Engineering and Technology 